\title{
Surgical Approaches to Retrosternal Goiter, When Sternotomy Is Mandatory? National Cancer Institute Experience (NCI), Cairo University, Egypt
}

\author{
Ahmed El Sayed Fathalla, Bahaa El Din Ahmed \\ National Cancer Institute, Cairo University, Giza, Egypt \\ Email:drasf1975@gmail.com, bahaaahmed897@yahoo.com
}

Received 17 March 2016; accepted 25 April 2016; published 28 April 2016

Copyright (C) 2016 by authors and Scientific Research Publishing Inc. This work is licensed under the Creative Commons Attribution International License (CC BY). http://creativecommons.org/licenses/by/4.0/

\section{Abstract}

Background: Retrosternal goiters (RG) are those lesions extending to occupy the thoracic cavity. They carry a surgical risk due to distorted anatomy, the minimal access, and the potential for great vessels or pleural injury. No other effective therapeutic alternative to surgery exists. Cervicotomy is still the surgical approach of choice, although a form of sternotomy may always be necessary for field extension and safe gland delivery. Materials and Methods: This is a single institution combined retrospective $\&$ prospective study including retrospective analysis of all cases presenting to the NCI, Cairo University with RG candidate for surgery between Jan. 2008 until the end of Dec. 2012, and a prospective study of all cases with the same presentation presenting to the NCI between Jan. 2013 until the end of Dec. 2015. Data was collected from archive of patients at the statistical department. Aims: To study the clinico-pathological characteristics, the presentation, workup, surgical approaches and postoperative complications of RG. Results: 42 patients were included $\&$ were divided into benign (34 patients, $80.9 \%$ ) and malignant groups (8 cases, $19.1 \%$ ). All patients $(100 \%)$ were adults ranging (19 to 73 years) with mean 53.1 years. There was a female predominance ( 36 female, $85.7 \%$ ) versus ( 6 males, 14.3\%). Median duration of symptomatology was 23 months ranging (6 - 53 months). 23 patients (54.7\%) were symptomatic while 19 cases $(45.3 \%)$ accidently discovered. Mean tumor size was $9.97 \mathrm{~cm}$ in the benign group and $11.1 \mathrm{~cm}$ in the malignant group. 31 patients $(73.8 \%)$ were euthyroid, $9(21.4 \%)$ were thyrotoxic and 2 $(4.7 \%)$ were hypothyroid. All patients $(100 \%)$ underwent total thyroidectomy. The commonest approach was cervicotomy ( 33 cases, 78.6\%), while a type of sternotomy was done in 9 cases $(21.4 \%) .2$ cases $(4.7 \%)$ received postoperative radiation therapy \& 4 cases $(9.5 \%)$ received postoperative radioactive iodine. No perioperative mortality occurred $\&$ the overall morbidity was 6 cases $(14.2 \%)$ in the benign group and 2 cases $(4.7 \%)$ in the malignant group $(4.7 \%)$. The median follow up period was 17.5 months. The median overall survival (OS) was 39.4 months and 
the median disease free survival (DFS) was 9.8 months for the malignant group. Conclusion: Cervicotomy is a safe favorable approach to remove a RG. Intraoperative field extension up to a form of sternotomy may be necessary for gland delivery with increasing operating time, hospital stay and morbidity. Postoperative morbidity is mainly due to the respiratory, recurrent laryngeal nerve palsy and hypoparathyroidism which is mainly increased when sternotomy is performed.

\section{Keywords}

\section{Retrosternal Goiter, Mediastinal, Sternotomy, Cervicotomy}

\section{Introduction}

Goiter is a term derived from the Latin word tumidum gutter, meaning swollen throat, and is defined as a thyroid that is twice the normal size or over $40 \mathrm{~g}$. $\mathrm{RG}_{\mathrm{s}}$ are those goiters extending beyond the thoracic inlet. It was first described in 1749 by Albrecht von Haller who considered these thyroid enlargements as a surgical challenge [1].

They usually remain asymptomatic for long time, however, they have the potential for sudden enlargement secondary to hemorrhage, cystic degeneration or malignant change resulting in air way compromise that can be life threatening [2].

They occur in $1 \%$ - 20\% of patients undergoing thyroidectomes. RG may be partially or completely intrathoracic. The complete intrathoracic goiter lies totally within the anterior mediastinum and is separated from the cervical thyroid gland receiving its blood supply either from aortic arch, innominate or internal mammary vessels. In practice, a RG is diagnosed when the retrosternal extension exceeds $2 \mathrm{~cm}$ below the manubrium on CT scanning of the neck and chest. The majority of these goiters are resected safely through a cervical incision although, in $1 \%-15 \%$ of patients, a form of sternotomy is needed to allow a safe exposure for goiter delivery [3].

Although it is possible to achieve very low morbidity and even zero mortality for thyroidectomy, RG carry a surgical risk due to distorted anatomy of the huge mass, the minimal access to the intrathoracic location from the cervical exposure, and the potentiality for great vessels or pleural injury. Despite these complications, no other effective therapeutic alternative to surgery exists. Symptomatic patients are more willing to accept surgery, while asymptomatic ones are often reluctant to consider surgery, especially when a form of sternotomy may be required [4] [5].

To predict a possibility for sternotomy, clinical and radiological risk assessment associated with the informed patient choice are used. A long history of retrosternal extension above 160 months is the main clinical risk. CT evidence of an ectopic gland, a dumbbell-shaped lesion, a conical-shaped goiter constricted by the thoracic inlet or a thoracic component larger than the thoracic inlet predicts the need to sternotomy. Thyroid gland density, posterior mediastinal location and subcarinal extension measured by CT imaging, are other independent risk factors. The gland density is the strongest factor and increases the sternotomy risk 47-fold [6]-[9].

Finally, the informed consent should involve a discussion that patients with bilateral multinodular goiter and intrathoracic extension undergoing resection via cervicotomy, there is an independent increased risk of complications, mainly the recurrent laryngeal nerve injury. After this explanation, patients may be unwilling to accept the increased risks of cervicotomy versus those of combined cervicotomy and sternotomy [10].

This cohort aims to study the clinico-pathological features of RG and to determine the clinical presentation, workup, frequent surgical complications and outcome of management.

\section{Materials and Methods}

This is a single institution combined retrospective \& prospective study. It included a retrospective analysis of all cases presented NCI-Cairo University with RG candidate for surgery from Jan 2008 untill the end of Dec 2012 and prospective analysis of all cases with the same presentation presented to the NCI from Jan 2013 untill the end of Dec 2015. Data was collected from patients archive at the statistical department. Inclusion criteria for RG was those goiters with either their lower extent passing the fourth thoracic vertebra or at least $50 \%$ of the mass lies within the thorax. A total number of 42 cases were included divided into 2 main groups (benign and malignant). Each patient record was revised for age, sex, clinical presentation, imaging, pathology, operative notes, 
treatment options given, and postoperative complications. For the malignant group, outcome analysis was done including OS and DFS. Treatment failure patterns were classified into local recurrence and distant metastasis. Ethical clearance for the conduction of this study was obtained from our institute ethical committee.

\section{Results}

Patients were divided into 2 groups (benign \& malignant).

\section{Clinical Features}

This cohort included 42 patients with RG. All patients (100\%) were adults (above 18 years) ranging in age from (19 to 73 years) (mean 53.1 years). There was a female predominance among all our patients (36 female, 85.7\%) versus ( 6 males, 14.3\%). The median duration of symptomatology was 23 months (range; 6-53 months). 23 patients (54.7\%) showed a significant symptomatology while 19 cases $(45.3 \%)$ were asymptomatic and was accidently discovered. The commonest presentation was dyspnea (29 cases, 69.1\%) followed by neck swelling (20 cases, 47.6\%). Other symptomatology included: cough (15 cases, 35.7\%), chest infection (11 cases, 26.1\%) chest infection (11 cases, 26.1\%), SVC syndrome (10 cases, 23.8\%), chest pain (9 cases, 21.4\%) and bony aches (6 cases, 14.3\%). Table 1 describes different clinical presentations in both the benign and the malignant groups.

Table 1. Symptomatology, investigation \& complication in our cohort.

\begin{tabular}{|c|c|c|c|}
\hline \multicolumn{4}{|c|}{$\begin{array}{l}\text { Clinical presentations in the benign \& malignant groups: } \\
\text { N.B., more than one complaint may be present in the same patient }\end{array}$} \\
\hline Presentation & Benign (34 cases) & Malignant (8 cases) & Total (42 cases) \\
\hline Dyspnea & $22(52.4 \%)$ & $7(16.6 \%)$ & $29(69.1 \%)$ \\
\hline Neck swelling & 17 (40.4\%) & $3(7.1 \%)$ & $20(47.6 \%)$ \\
\hline Cough & $11(26.2 \%)$ & $4(9.5 \%)$ & 15 (35.7\%) \\
\hline Chest infection & $9(21.4 \%)$ & $2(4.7 \%)$ & $11(26.1 \%)$ \\
\hline SVC syndrome & $7(16.6 \%)$ & $3(7.1 \%)$ & $10(23.8 \%)$ \\
\hline Chest pain & $4(9.5 \%)$ & $5(11.9 \%)$ & $9(21.4 \%)$ \\
\hline Bony aches & $2(4.7 \%)$ & $4(9.5 \%)$ & $6(14.3 \%)$ \\
\hline \multicolumn{4}{|c|}{$\begin{array}{l}\text { Preoperative radiological investigations in the benign \& malignant groups: } \\
N . B, \text { more than one investigation may be done to the same patient }\end{array}$} \\
\hline Investigation & Benign group & Malignant group & Total \\
\hline Chest x-ray & $34(100 \%)$ & $8(100 \%)$ & $42(100 \%)$ \\
\hline CT scan & 33 (97.1\%) & $7(87.5 \%)$ & 40 (95.2\%) \\
\hline Thyroid scan & $16(47.1 \%)$ & $5(62.5 \%)$ & $21(50 \%)$ \\
\hline Neck ultrasonography & 17 (50\%) & $3(37.5 \%)$ & $20(47.6 \%)$ \\
\hline CT Angiography (CTA) & $13(38.2 \%)$ & $6(75 \%)$ & 19 (45.2\%) \\
\hline MRI & $6(17.6 \%)$ & $2(25 \%)$ & 8 (19.1\%) \\
\hline Bone scan & $2(5.4 \%)$ & $5(62.5 \%)$ & $7(16.7 \%)$ \\
\hline MR Angiography (MRA) & $3(8.8 \%)$ & $1(12.5 \%)$ & $4(9.5 \%)$ \\
\hline \multicolumn{4}{|c|}{$\begin{array}{l}\text { Postoperative complications in the benign \& malignant groups: } \\
\text { N.B., more than one complication may be present in the same patient }\end{array}$} \\
\hline Complication & Benign group & Malignant group & Total \\
\hline Chest infection & $4(9.5 \%)$ & $5(11.9 \%)$ & $9(21.4 \%)$ \\
\hline Lung collapse & $3(7.1 \%)$ & $5(11.9 \%)$ & $8(19.1 \%)$ \\
\hline Hypocalcaemia & $2(4.7 \%)$ & 4 (9.5\%) & $6(14.3 \%)$ \\
\hline Hypothyroidism & $1(2.3 \%)$ & $3(7.1 \%)$ & $4(9.5 \%)$ \\
\hline Pneumothorax & $2(4.7 \%)$ & $1(2.3 \%)$ & $3(7.1 \%)$ \\
\hline RLN. paralysis & 0 & $3(7.1 \%)$ & $3(7.1 \%)$ \\
\hline Postoperative bleeding & $1(2.3 \%)$ & $2(4.7 \%)$ & $3(7.14 \%)$ \\
\hline Tracheomalacia & $2(4.7 \%)$ & 0 & $2(4.7 \%)$ \\
\hline
\end{tabular}




\section{Pathology}

34 of our patients (80.9\%) showed a benign pathology while malignant pathology was present in 8 cases (19.1\%). Neoplasms were grossly identified and ranged in size from 8 to $20 \mathrm{~cm}$ (mean $9.97 \mathrm{~cm} \&$ SD 3.13) in the benign group while in the malignant group it ranged in size from 9 to $14 \mathrm{~cm}$ (mean $11.1 \mathrm{~cm} \& \mathrm{SD} 2.32$ ). Table 2 shows pathological types among the benign and malignant groups.

\section{Staging}

Malignant tumors were staged according to TNM staging system where 5 of our cases (11.9\%) were stage I, 2 cases $(4.7 \%)$ were stage III (locally advanced disease), and only one case $(2.3 \%)$ was stage IV. There was no stage II in the current study.

\section{Investigation}

Most of the patients were euthyroid (31 cases, 73.8\%), whereas 9 cases (21.4\%) were thyrotoxic and required preoperative preparation with non selective b-blockers (propranolol) and lugol's iodine drops for 2 weeks. Finally 2 cases only (4.7\%) were hypothyroid where they needed preoperative replacement with oral thyroxine for 2 weeks. Other radiological investigation needed in this work was presented in Table 1.

\section{Treatment}

All our patients underwent total thyroidectomy. Only 2 patients in the malignant group underwent primarily unilateral hemithyroidectomy where postoperative pathology revealed papillary thyroid carcinoma larger than 2 $\mathrm{cm}$ in size and completion thyroidectomy was done shortly after. The commonest surgical approach in this cohort was the cervical approach (33 cases, 78.6\%). 9 cases (21.4\%) required breaching of the sternum either partially, totally or just manuburotomy. Different surgical approaches done in our study are presented in Table 3. For the malignant group (8 cases), 2 cases received postoperative adjuvant radiation therapy due to extracapsular tumor extension and 4 cases received adjuvant postoperative radioactive iodine.

There was no perioperative mortality in our study and the overall postoperative morbidity was 6 cases in the benign group (14.2\%) and 2 cases (4.7\%) in the malignant group (4.7\%). Different postoperative complications encountered in our study are shown on Table 1.

\section{Survival}

The maximum period of follow up in our cohort was 43 months while the minimum period was 6 months with a median period of follow up of 17.5 months. The median overall survival time was 39.4 months (standard error; 7.4 with 95\% confidence interval; 18.7 - 47.8 months) (22 and 23 and figures (64 and 65) show the overall and the disease free survival in our malignant group. The median disease free survival time was 9.8 months (standard error; 2.07 with 95\% confidence interval; 5.75 - 13.86 months). The median overall 5 years survival and the median overall disease free survival are presented in Figures 1-4.

Table 2. Different pathological types among the benign and malignant groups.

\begin{tabular}{|c|c|c|c|}
\hline Group & Male & Female & Total \\
\hline Benign thyroid swellings: & 4 & 30 & $34(81 \%)$ \\
\hline - $\quad$ M.N.G (nodular hyperplasia) & 2 & 11 & $14(33.4 \%)$ \\
\hline - Diffuse hyperplasia & 1 & 8 & $9(21.4 \%)$ \\
\hline - M.N.G with Macrofollicular adenoma & 1 & 6 & $7(16.7 \%)$ \\
\hline - Hurthle cell adenoma & - & 4 & $4(9.5 \%)$ \\
\hline Thyroid malignancies: & 2 & 6 & $8(19 \%)$ \\
\hline - Papillary carcinoma & - & 4 & $4(9.5 \%)$ \\
\hline - Medullary carcinoma & 2 & - & $2(4.8 \%)$ \\
\hline - Anaplastic carcinoma & - & 2 & $2(4.8 \%)$ \\
\hline Total: & $6(14.2 \%)$ & $36(85.7 \%)$ & $42(100 \%)$ \\
\hline
\end{tabular}


Table 3. Surgical approach in relation to pathology in our study.

\begin{tabular}{|c|c|c|c|}
\hline Approach & No. & Pathology & No. \\
\hline Cervicotomy: & $\begin{array}{l}33 \text { cases } \\
\text { (78.6\%) }\end{array}$ & $\begin{array}{l}\text { - } \text { M.N.G (nodular hyperplasia) } \\
\text { - } \text { Diffuse hyperplasia } \\
\text { - } \text { Hurthle cell adenoma } \\
\text { - } \text { Papillary carcinoma } \\
\text { - } \text { Medullary carcinoma } \\
\text { - }\end{array}$ & $\begin{array}{c}11 \\
9 \\
5 \\
4 \\
2 \\
1 \\
1\end{array}$ \\
\hline Cervicotomy with manuburotomy: & $\begin{array}{c}7 \text { cases } \\
(16.7 \%)\end{array}$ & $\begin{array}{ll}\text { - } & \text { M.N.G (nodular hyperplasia) } \\
\text { - } & \text { Papillary carcinoma } \\
\text { - } & \text { Medullary carcinoma }\end{array}$ & $\begin{array}{l}3 \\
2 \\
1 \\
1\end{array}$ \\
\hline Cervicotomy with partial sternotomy & $1(2.4 \%)$ & - Anaplastic carcinoma & 1 \\
\hline Cervicotomy with complete sternotomy & $1(2.4 \%)$ & - Papillary carcinoma & 1 \\
\hline
\end{tabular}

Overall Survival

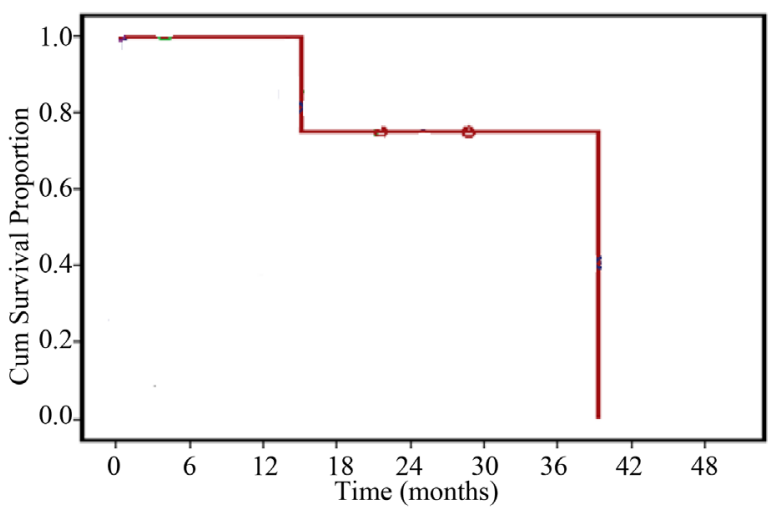

Disease Free Survival

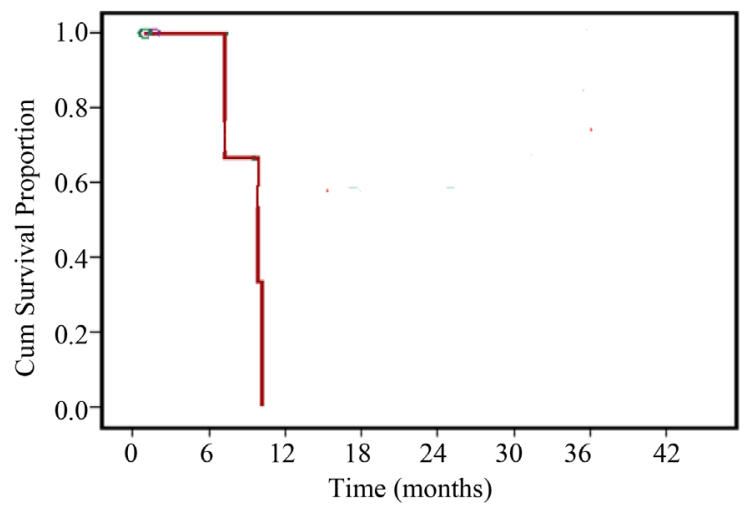

Figure 1. Statistical graph showing the overall survival and disease free survival in the malignant group.
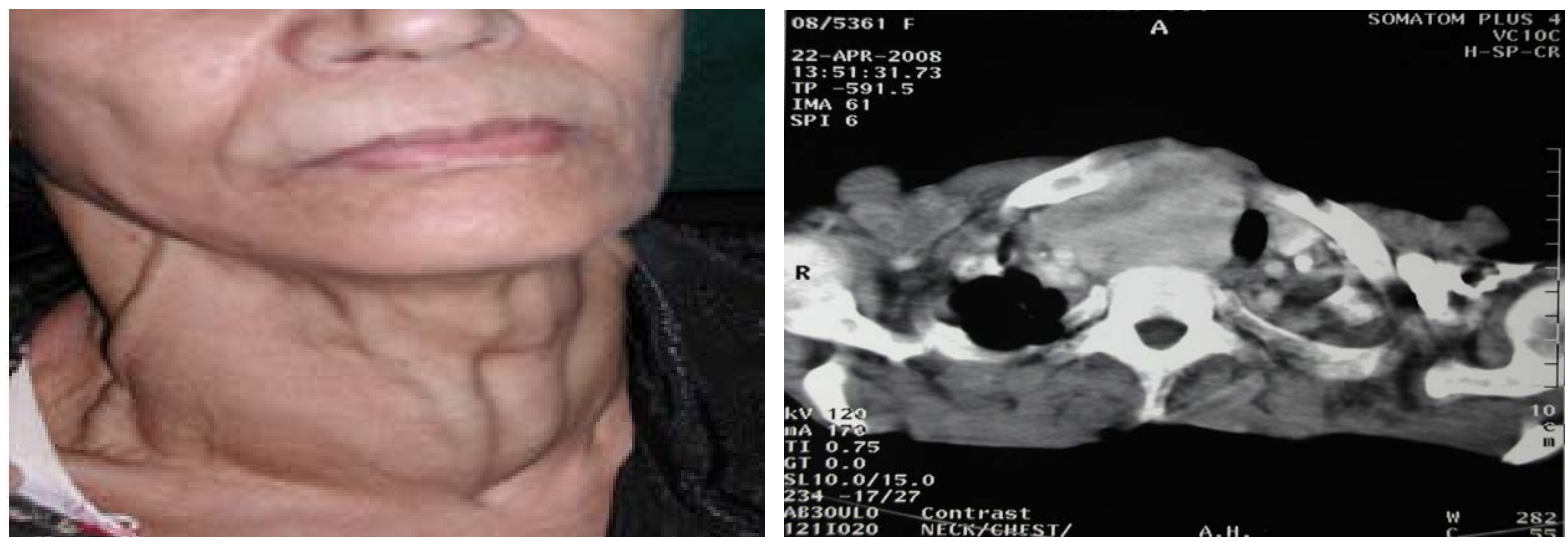

Figure 2. One of our patients with superior mediastinal syndrome with CT scanning (axial view) showing the huge RG.

\section{Discussion}

Intrathoracic goiters are divided into three types: 1) Small retrosternal extension of a mainly cervical goiter (RG); 2) Partial intrathoracic goiter, where its major portion is situated within the thorax; and 3) Complete intrathoracic 

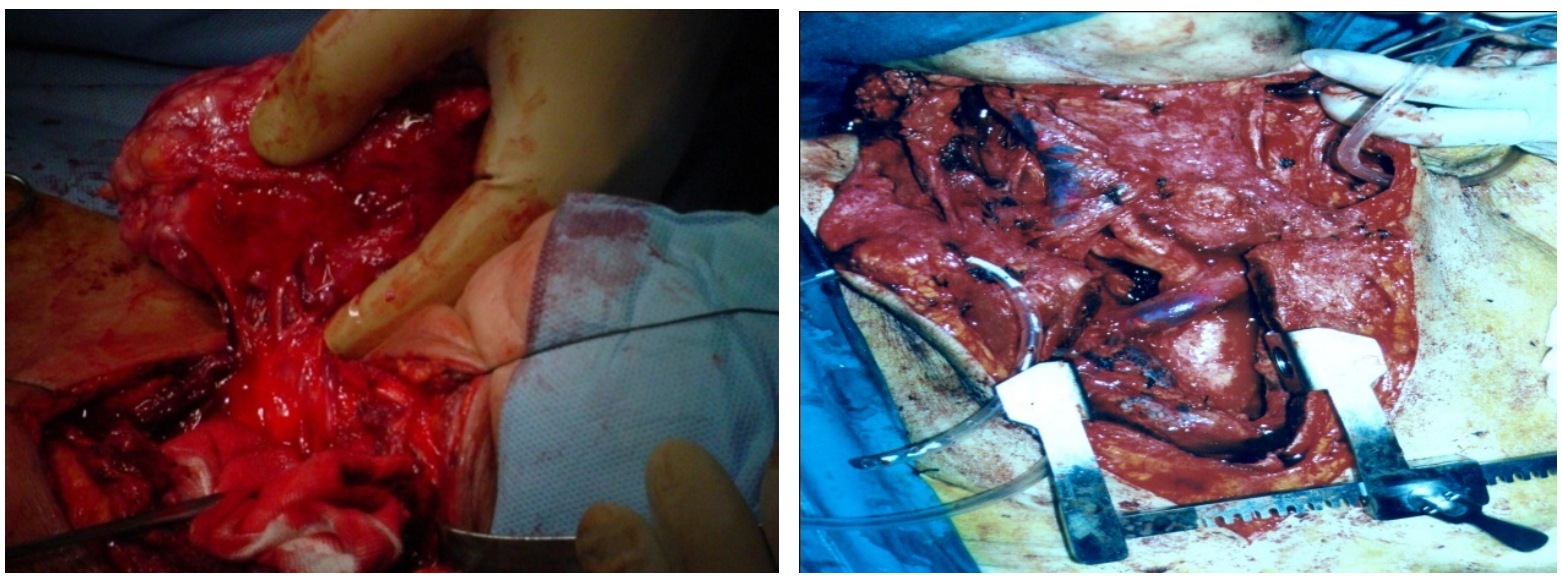

Figure 3. Intra operative view showing cervicotomy (left) and partial sternotomy (on right) for removal of another huge RG.
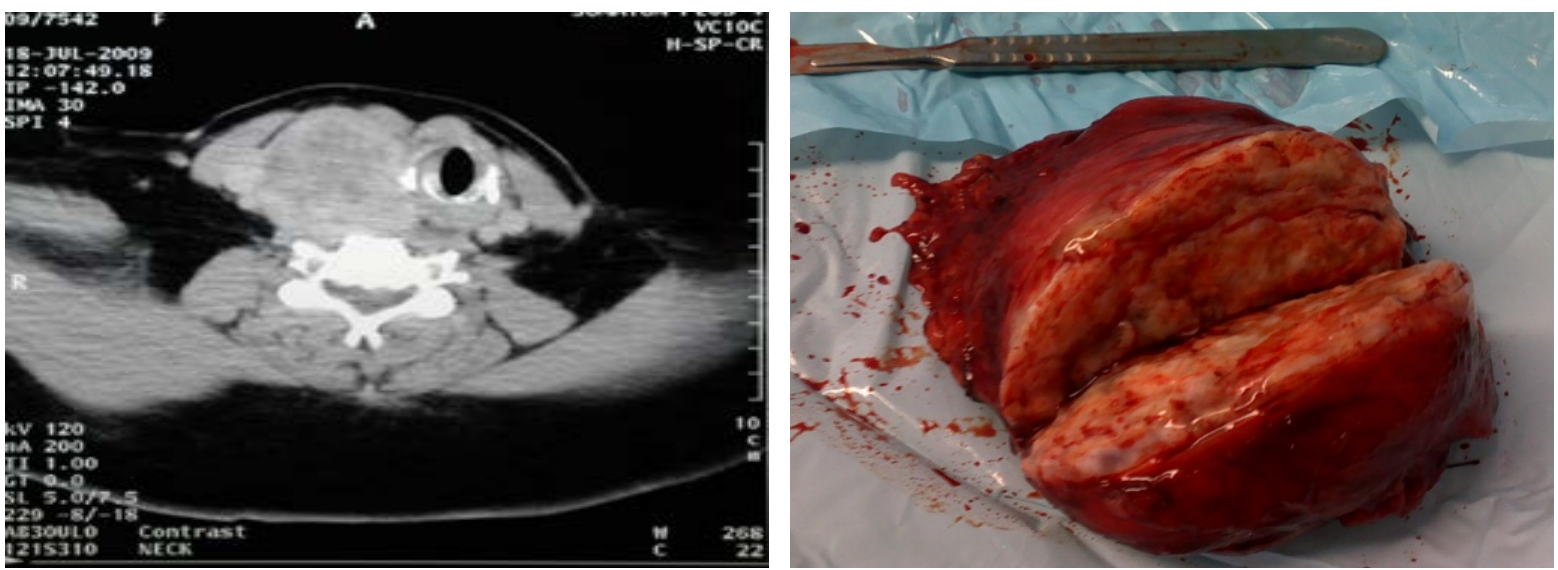

Figure 4. Showing CT scanning (axial view) of another RG (left) with the postoperative specimen after resection (right).

(ectopic) goiter, in which the entire goiter lies within the thorax. The small retrosternal extension is by far the most common and accounts for over $80 \%$ of cases. Most intrathoracic goiters are benign nontoxic multinodular goiters. Occasionally it may be toxic. An occult papillary thyroid carcinoma may be found in a RG with an incidence of $1.5 \%$. In this work, all our cases were retrosternal extension of a main cervical goiter. Most of patients were euthyroid (31 cases, 73.8\%), whereas 9 cases (21.4\%) were thyrotoxic. Finally 2 cases only (4.7\%) were hypothyroid. 8 patients showed malignant pathology ( 4 cases; 9.5\% were papillary, 2 cases; 4.8\% were medullary and the last 2 cases; $4.8 \%$ were anaplastic). There was no follicular thyroid carcinoma in this cohort [11].

Surgery for RG should always be considered, even in elderly patients because of the high risk of tracheal compression and the low morbidity of the surgery. Obviously, the earlier in the course of development of a RG surgery is undertaken, the easier, simpler and safer is the surgical procedure. The large majority of goiters could be removed transcervically, regardless of their location and extension. A form of sternotomy either partially or totally is usually needed in cases of recurrent goiter, ectopic goiter, invasive carcinoma, Superior vena cava syndrome, airway compression, dysphagia, retrotracheal goiter, or crossover goiters. However, in the rare situation of complete aberrant goiters they are removed through median sternotomy or even the standard posterolateral thoracotomy. In this cohort (33 patients, $78.6 \%$ ) were removed through cervicotomy which was quite enough and safe while a form of sternotomy was needed in (9 cases, 28.4\%). There was no ectopic goiter in our study and thus the standard thoracotomy was not performed [12].

Ultrasound can suspect a RG when their inferior margins are not visualized. CT scanning of the neck and upper chest gives a bright view of the extension and appreciates the size, content and relations with mediastinal vessels, trachea and the esophagus. MRI allows multiplanar views. In this study, CT scanning was the investiga- 
tion of choice done in 40 patients (95.2\%) and was conclusive for the preoperative anatomical planning for surgery [8] [13].

Multiple extensions of the goitre, previous thyroid surgery and posterior plunging goiters are suggestive of preoperative difficulties and postoperative morbidity. The main postoperative complication is development of hematoma. It may cause acute respiratory distress even with a good drain. Tracheomalacia is another cause of respiratory compromise especially in long standing cases that may result in mechanical invasive ventilation or permanent tracheostomy. In this work the commonest complication was chest infection (9 cases, 21.4\%) followed by lung collapse (8 cases, 19.1\%). Tracheomalacia occurred in 2 of our patients in the benign group; both gave a long history of goiter (46 months \& 53 months) [14].

The risk of recurrent nerve injury is still higher in surgery for RG. In most studies it occurs between $2 \%$ and $10 \%$ in the hand of experienced surgeons. There is always a risk during gland extraction especially on the right side. This risk seems higher with sternotomy than cervical approach $(3 \%-8 \%)$ in most studies. Visual nerve identification is considered mandatory in our center for surgeries of the thyroid \& the parathyroid. In this work RLN injury occurred in 3 cases (7.1\%) of the malignant group (one case was previously explored where nerve identification was impossible, second showed recurrent disease with malignant adhesions with the trachea taking the nerve involved, the third was injured during partial thoracotomy as it was adherent to level VI group of cervical nodes during central compartment lymphadenectomy "level VI \& VII") [15] [16].

The parathyroid glands also are more exposed to surgical trauma even when a form of sternotomy is performed. Their identification is usually difficult, especially for the lower glands that are located under the goiter or in a very low position in the thyrothymic tract. They can be easily injured during the dissection and extraction of goitre. The hypoparathyroidism seems more important with sternotomy (2.8\%) \& the risk is further increased in cases with previous surgery where the dissection becomes difficult. In our study hypocalcaemia appeared in 6 cases $(14.3 \%), 2$ cases $(4.7 \%)$ was in the benign group and 4 (9.5\%) in the malignant group. 3 of these cases (50\%) developed hypoparathyroidism after a form of sternotomy. Still malignant transformation is equivalent in RG to those residing entirely in the neck [17].

It is obvious that there is no consensus about the predictive factors of sternotomy. Burns et al. defined that CT adherence to the surrounding mediastinal structures and extension of the goitre to, or below, the aortic arch are significant factors of sternotomy. De Perrot et al. stated that goiters reaching $10 \mathrm{~cm}$, recurrent goiters, invasive carcinoma or ectopic goitre are in need of sternotomy for resection. Cohen et al. identified four factors of sternotomy in RG; Malignancy, extension into the posterior mediastinum, substernal extension inferior to the level of the aortic arch, and the lack of a solid attachment between the cervical and mediastinal components of the thyroid gland. In our work the median duration of symptomatology was 23 months. 23 patients (54.7\%) showed with a significant symptomatology while 19 cases (45.3\%) were asymptomatic and was accidently discovered. The mean neoplasms size was $9.97 \mathrm{~cm}$ in the benign group \& $11.1 \mathrm{~cm}$ for the malignant group [18]-[20].

\section{Conclusion}

Without any contraindications, patients with a RG should undergo early surgery before reaching acute airway obstruction or malignant transformation. With surgery, mortality is rare if any and the morbidity is also very low, especially in asymptomatic patients.

\section{References}

[1] Haller, A. (1749) Disputationes Anatomicae Selectae. Vandenhoeck, Gottingen, 96.

[2] Erbil, Y., Bozbora, A., Barbaros, U., Ozarmagan, S., Azezli, A. and Molvalilar, S. (2004) Surgical Management of Substernal Goiters: Clinical Experience of 170 Cases. Surgery Today, 34, 732-736. http://dx.doi.org/10.1007/s00595-004-2823-4

[3] Hedayati, N. and McHenry, C.R. (2002) The Clinical Presentation and Operative Management of Nodular and Diffused Substernal Thyroid Disease. Annals of Surgery, 68, 245-252.

[4] Testini, M., Nacchiero, M., Miniello, S., Ianora, A.S., Piccinni, G. and Di Venere, B. (2005) Management of Retrosternal Goiters: Experience of a Surgical Unit. International Surgery, 90, 61-65.

[5] Latteri, S., Saita, S. and Potenza, E. (2000) Intrathoracic Goiter: Experience with 61 Surgically Treated Cases. Chirurgia Italiana, 52, 139-145.

[6] Casella, C., Pata, G., Cappelli, C. and Salerni, B. (2010) Preoperative Predictors of Sternotomy Need in Mediastinal 
Goiter Management. Head \& Neck, 32, 1131-1135. http://dx.doi.org/10.1002/hed.21303

[7] Riffat, F., Del Pero, M.M., Fish, B. and Jani, P. (2013) Radiologically Predicting When a Sternotomy May Be Required in the Management of Retrosternal Goiters. Annals of Otology, Rhinology \& Laryngology, 122, 15-19. http://dx.doi.org/10.1177/000348941312200104

[8] Qureishi, A., Garas, G., Tolley, N., Palazzo, F., Athanasiou, T. and Zacharakis, E. (2013) Can Pre-Operative Computed Tomography Predict the Need for a Thoracic Approach for Removal of Retrosternal Goitre? International Journal of Surgery, 11, 203-208. http://dx.doi.org/10.1016/j.ijsu.2013.01.006

[9] Sari, S., Erbil, Y., Ersöz, F., Saricam, G., Salmaslioğlu, A., Işsever, H., et al. (2012) Predictive Value of Thyroid Tissue Density in Determining the Patients on Whom Sternotomy Should Be Performed. Journal of Surgical Research, 174, 312-318. http://dx.doi.org/10.1016/j.jss.2011.01.019

[10] Zambudio, A.R., Rodríguez, J., Riquelme, J., Soria, T., Canteras, M. and Parrilla, P. (2004) Prospective Study of Postoperative Complications after Total Thyroidectomy for Multinodular Goiters by Surgeons with Experience in Endocrine Surgery. Annals of Surgery, 240, 18-25. http://dx.doi.org/10.1097/01.sla.0000129357.58265.3c

[11] Pace-Asciak, P. and Higgins, K. (2008) Management of Intrathoracic Goiter. Canadian Journal of Surgery, 51, 111112.

[12] Rugiu, M.G. and Piemonte, M. (2009) Surgical Approach to Retrosternal Goiter: Do We Still Need Sternotomy? Acta Otorhinolaryngologica Italica, 29, 331-338.

[13] Tomiyama, N., Honda, O., Tsubamoto, M., Inoue, A., Sumikawa, H., Kuriyama, K., Kusumoto, M., Johkoh, T. and Nakamura, H. (2009) Anterior Mediastinal Tumors (Diagnostic Accuracy of CT and MRI). European Journal of Radiology, 69, 280-288. http://dx.doi.org/10.1016/j.ejrad.2007.10.002

[14] Shen, W.T., Kepebew, E., Duh, Q.Y. and Clark, O.H. (2004) Predictors of Airway Complications after Thyroidectomy for Substernal Goiter. Archives of Surgery, 139, 656-660. http://dx.doi.org/10.1001/archsurg.139.6.656

[15] Dralle, H., Sekulla, C., Lorenz, K., Brauckhoff, M. and Machens, A. (2008) Intraoperative Monitoring of the Recurrent Laryngeal Nerve in Thyroid Surgery. World Journal of Surgery, 32, 1358-1366. http://dx.doi.org/10.1007/s00268-008-9483-2

[16] Calo, P.G., Pisano, G., Medas, F., Tatti, A., Tuveri, M. and Nicolosi, A. (2012) Risk Factors in Reoperative Thyroid Surgery for Recurrent Goitre: Our Experience. Il Giornale di Chirurgia, 14, 335-338.

[17] Kacprzak, G., Karas, J., Rzechonek, A. and Blasiak, P. (2012) Retrosternal Goiter Located in the Mediastinum: Surgical Approach and Operative Difficulties. Interactive Cardiovascular and Thoracic Surgery, 15, 935-937. http://dx.doi.org/10.1093/icvts/ivs339

[18] Burns, P., Doody, J. and Timon, C. (2008) Sternotomy for Substernal Goitre: An Otolaryngologist’s Perspective. The Journal of Laryngology \& Otology, 122, 495-499. http://dx.doi.org/10.1017/s0022215107000047

[19] De Perrot, M., Fadel, E., Mercier, O., Farhamand, P., Fabre, D., Mussot, S. and Dartevelle, P. (2007) Surgical Management of Mediastinal Goiters: When Is Sternotomy Required? The Journal of Thoracic and Cardiovascular Surgery, 55, 39-43. http://dx.doi.org/10.1055/s-2006-924440

[20] Cohen, J.P. (2009) Substernal Goiters and Sternotomy. The Laryngoscope, 119, 683-688.

http://dx.doi.org/10.1002/lary.20102 